\title{
Functionality Assessment of Building a Microclimate System Utilising Solar Energy in a Cold Climate
}

\author{
Karolis Januševičius ${ }^{1, *}$ - Juozas Bielskus² - Vytautas Martinaitis ${ }^{1}$ \\ 1 Vilnius Gediminas Technical University, Faculty of Environmental Engineering, Lithuania \\ 2 Vilnius Gediminas Technical University, Civil Engineering Research Centre, Lithuania
}

\begin{abstract}
Bringing clean and affordable energy to the market is one of the goals of sustainable development set by the United Nations. Thermal comfort is an important aspect of efficient energy use, which plays a crucial role in ensuring health and well-being in the built environment. The majority of energy in the building sector is consumed by microclimate systems that provide thermal comfort for occupants. Design strategies, such as passive and active solar and thermal mass utilisation, reduce heat demand. When aiming to optimise thermal comfort, a reasonable combination is important in order to increase the utilisation of clean renewable energy, while conserving other resources.

In this paper, a method to generate design charts is proposed to assess early design options. It aids in the selection of design parameters, based on targeted seasonal thermal comfort as a function of a complex microclimate system. In order to explore the interaction between design variables, a TRNSYS simulation model was used. An analysis of comfort conditions (based on the EN ISO 7730 method) in building spaces was performed to assess functionality. The simulation model accounted for the thermal constant in building spaces, solar utilisation and gain through glass surfaces, solar collectors and active accumulation, energy transportation, and distribution efficiency.

The presented case study results showed that the lack of space heating capacity (3/4 of the calculated quantity) could be compensated for by thermal mass and a solar thermal collector without compromising thermal comfort (the percentage of people dissatisfied (PPD) was below $10 \%)$. The highest solar fraction (36\%) was reached with the lowest fractions of space heating capacity (1/2 of the calculated quantity), due to increased demands, but this design option did not satisfy the thermal comfort conditions (PPD > $17 \%$ ).

Keywords: solar thermal; early design tool; thermal comfort

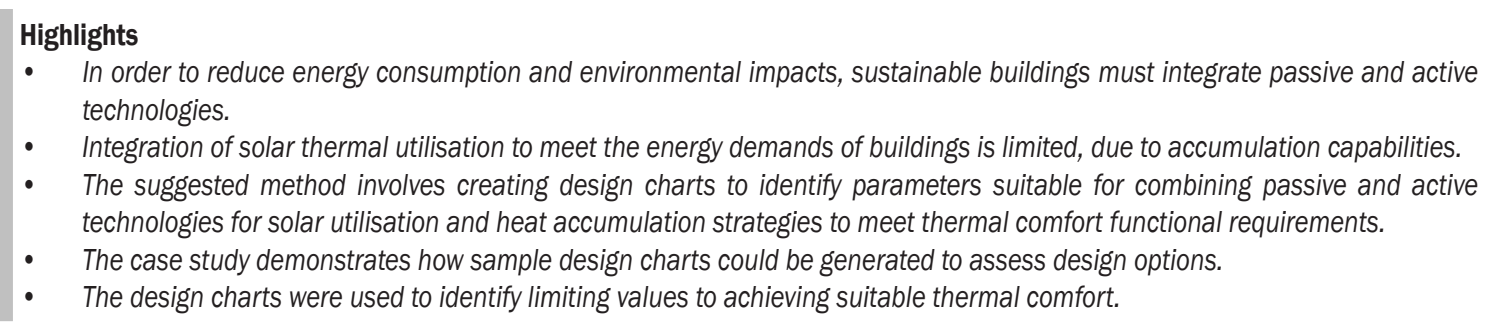

\section{INTRODUCTION}

In September 2015, the United Nations (UN) Assembly approved the sustainable development agenda [1]. According to this agenda, member countries must take action in order to improve the sustainability of the planet. Goals up until the year 2030 were set. Multiple aspects of the 17 sustainable development goals determined by the UN were aimed at increasing the utilisation of renewable energy and improving energy efficiency [2]. It is clear that these goals could only be met by using complex measures, in terms of the most influential consumers, i.e. the built environment, due to its high environmental impact [3]. In EU households, heating and hot water alone account for $79 \%$ (in industry $70.6 \%$ ) of total final energy consumption. Thus, it is important to focus on heating demands [4]. Approximately $84 \%$ of heating and cooling is still generated from fossil fuels, while only $16 \%$ is generated from renewable energy.
In order to fulfil the EU's climate and energy goals, the heating and cooling sector must sharply reduce its energy consumption and decrease its use of fossil fuels [5].

Integrated design efficiency and final product quality are highly dependent on primary actions at the initial stages of any project. According to value engineering principles [6], a function could be satisfied in different ways that allow for different performances. Those aspects determine the pathway characterized by [7], which specified that alternatives should be considered at the initial stage of design. In this phase, solutions can be integrated at the lowest resource cost. In this context, the cost of considering different design alternatives becomes an important aspect of an efficient design process.

When designing sustainable buildings, passive and active energy conservation solutions, in combination with renewable energy utilisation, play an important role. The primary function of a complex microclimate 
system is to ensure comfort for the occupants. A design process sets only a portion of the parameters, but overall thermal comfort expression is typically left unaddressed. Thermal comfort is one of the aspects, along with visual, acoustic, and indoor air quality, which ensures health, productivity, and the wellbeing of people inside the building. The function of creating thermal comfort is itself composed of multiple secondorder functions - ensuring sensible temperature, air velocity, and relative humidity suitable for occupant activity and clothing levels [8]. There are multiple models on how to determine thermal comfort, from the holistic person-environment systems approach to the deterministic stimulus-response models, which are mostly used in standards [9].

In cold climates, the most influential factor in terms of creating internal thermal comfort is space heating demand. Ensuring comfortable indoor environments in workspaces is one of the primary contributors to achieving better performance. Indoor environmental factors in workplaces should follow functional, as well as behavioural, requirements [10].

According to Pathak et al. [10], the functionality of the indoor environment (microclimate) can be described in terms of warmth, light, noise, space, and furniture. The most defined and parametrized among the five is thermal comfort [11] and [12]. Active and passive building microclimate subsystems influence the overall thermal comfort. One of the simplest and most effective ways of pursuing energy savings in buildings is by acting on its envelope, which represents the path for substantial heat flows [13]. A passive subsystem consists of the building envelope and the internal thermal mass. It is considered passive, because it does not consume energy to provide functionality. Active subsystems consist of heating, cooling, and ventilation systems, which consume energy to perform dedicated functions [14].

In order to most effectively utilise solar radiation, passive and active measures of heat accumulation should be used. Passive utilisation is implemented via glazing and thermal mass in the building structure. Active utilisation can be fulfilled using accumulation storage fed via thermal collectors. Other parameters, such as solar heat gain and infiltration caused by air change rate, influence the indoor environment [15]. Solar heat gains achieved through glazed building envelope elements are absorbed and accumulated in the building structure. Due to the temperature difference, heat is released from the thermal mass to the indoor space and this reduces heating energy consumption. Active microclimate systems ensure thermal comfort by supplying heat, cold air, fresh air, and light to a room. However, in this case, the focus is on space heating measures.

Despite the fact that solar energy is utilised to achieve microclimate needs, total demand could not be ensured, due to an inequality between consumption and generation. Achieving equality becomes more realisable as the thermal properties of the building envelope are increased, unlocking an increase in solar utilisation and a decrease in fossil fuel use for the needs arising in a built environment.

Significant daily, seasonal, and annual differences in solar radiation exist in northern countries. This variation influences the requirement for accumulation in a system that utilises solar energy for space heating and other services. It is possible to accumulate solar energy passively or actively. Passive solar utilisation is that used to heat a space without any additional energy required to run the process [16]. Solar gains collected through transparent envelope elements are accumulated in the thermal mass of a building. At night, the thermal mass at higher temperatures collects heat and reduces heating load for that period. The fact that natural thermal processes in a building may reduce the energy requirement for heating makes it possible to choose a lower design temperature for the winter [15]. Therefore, studies have already shown that the impact of different insulation-mass configurations on both heating / cooling consumption and indoor comfort varies, and often exhibits the opposite effects [17]. Physical thermal processes that take place in the building envelope may reduce the demand for heating energy [15]. Studies have shown that passive solar heating combined with energy-saving construction could reduce thermal heating requirements by up to $30 \%$ [18]. Other studies state that the decrease varies from several percent to more than $80 \%$ [19]. The latest research shows that by applying this combination, heating costs in the winter can be reduced by up to 58 $\%[20]$.

Passive solar heating of buildings using thermal storage in the walls has been a subject of many studies, particularly related to the Trombe wall [21] to [25]. Ordinary walls have also received research attention [13], [19] and [26] to [28]. A study [29] defined a new system combining an active-passive triple phase change material wall and a multi-surface through solar concentrators. It improved heat storage capacity of the wall interior by using the active method and could improve heat storage capacity of the phase change material (PCM) wallboards using the passive method. Other studies used PCM in cold climates to accumulate solar energy, which led to a $17.4 \%$ annual drop in heating demand [30]. 
Authors [28] analysed the simultaneous optimisation of the thickness and positions of insulation layers. The optimisation effects on the dynamic thermal characteristics of walls were also quantified. Active solar energy utilisation can be implemented by using solar collectors for water heating. Storage tank and solar collectors are the main components of any solar water heating system [31].

Heat storage is an important part of a solar collector system, which helps to manage differences in time, as well as between the use and production of heat. Study [32] analysed the contribution of solar-thermal and thermal energy storage systems to fulfilling thermal energy demand profiles. 48 case studies used 12 house types under average (smoothed) and actual (warmer) weather conditions, as well as continuous and intermittent comfort maintenance.

Significant research has been conducted in regards to solar systems for space heating or hot domestic water preparation with solar collectors [30] to [33]. One study [34] presented a simplified method for optimising the key parameters of solar water heating systems based on life-cycle energy analysis, taking the phenomenon of energy mismatch into consideration.

An overview of the research shows a lack of studies in the holistic assessment of systems that integrate active and passive accumulation. Specifically, those using heat storage tanks with thermal mass in building structures were lacking in the literature. In addition, active and passive solar utilisation by solar collectors and glazing were absent in the research. The goal of this article is to examine the effects of combined solutions on thermal comfort [8]. The following section presents the method that expresses the design parameters for the system, combining thermal mass and solar utilization to ensure thermal comfort.

\section{METHODOLOGY}

In order to assess the degree of function fulfilment, the functionality (or functional efficiency) term was used. The functionality of a complex microclimate system was measured using the thermal comfort model created by Fanger [35] and adopted as standard [8]. By employing mathematical functions expressing the predicted mean vote of a statistical building occupant, the percentage of dissatisfied people (occupants) can be expressed. The Fanger thermal comfort model has a limiting value of $5 \%$ dissatisfied people. Lower values are not possible according to the model, due to the differences in human thermal sensation. This value indicates that the function of ensuring thermal comfort for occupants is satisfied at the highest level.

This paper presents an algorithm, which was used to generate design charts for the initial assessment of suitable options at the initial design phase. The algorithm expressing the workflow of design chart creation is shown in Fig. 1.

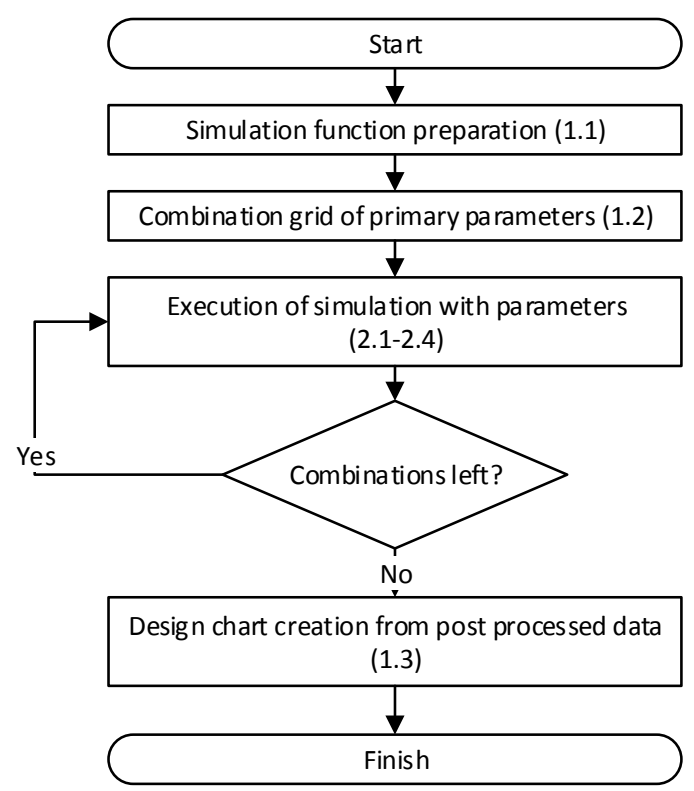

Fig. 1. Workflow of design chart creation on the basis of the proposed method

This tool helps designers quickly assess synergies in solar energy and heat accumulation utilisation in terms of the requirements for thermal comfort of building occupants. The execution of the provided algorithm results in design charts that can be used to predict design performance with various parameter combinations. Being able to consider a variety of design parameters and select the most appropriate one, or identify how the design should be adjusted, are the main benefits of the proposed method.

\subsection{Preparation of the Design Function for Parametric Analysis}

In order to determine the feasibility of utilising solar energy and heat accumulation methods and to quantify the interaction with internal thermal comfort, a calculation model was developed using TRNSYS software. The model was carefully parameterized using text variables and proper output files. The model was then saved as a *.dck file. The main output parameters used to guide the design decision were 
determined on the basis of the algorithm presented in EN ISO 7730[8].

The execution of procedures was wrapped into a MATLAB function, which ran the following sequence:

1. Within MATLAB, the *.dck was copied so as not to alter the original file.

2. MATLAB searched for and replaced the values of any design variables. Simulation variables in the *.dck template file were provided as MATLAB function inputs.

3. The updated $*$.dck file was saved.

4. The simulation then ran in the TRNSYS environment. The updated *.dck file was executed by TRNEXE.exe using the dos(*) command in MATLAB, which was a simple command line access function.

5. After running the simulation, the results were aggregated as an output.

6. Temporary files created by the simulation were removed.

This function allowed for parametric runs to be conducted to explore the field of design parameters and to create surface functions expressing the relation to thermal comfort.

\subsection{Set up and Execution of Parametric Analysis}

The purpose of parametric analysis is to generate consistent performance data. The solution developed using this approach is of higher resolution than a single minimum or maximum point obtained using optimisation methods. The knowledge presented in a visual allows for faster understanding of the change related to a performance function in relation to input parameters.

The execution of the created MATLAB function used specific inputs from the parameter grid results in the assessed thermal comfort as well as solar fraction values. The function was then executed with each parameter set in the loop, until there were no unsimulated sets left.

The results of the parametric analysis were postprocessed and presented as two overlaid surfaces. The MATLAB functionality was used to produce the graphs. The design charts represented the summary of simulation results. There were limited possibilities for extrapolation of design results if the explored range was limited. Due to the inconsistent behaviour of the interaction between the design parameters, it was more appropriate to expand the range of parametric analysis. Thus, extreme combinations were included in order to increase prediction accuracy. The structure of possible combinations is shown in Fig. 2.

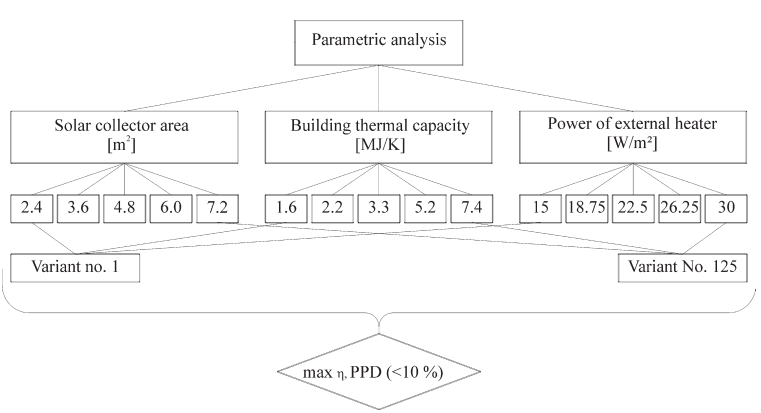

Fig. 2. Workflow of design chart creation on the basis of the proposed method

The values of solar collector absorber area varied in the parametric analysis from $2.4 \mathrm{~m}^{2}$ to $7.2 \mathrm{~m}^{2}$ in increments of $1.2 \mathrm{~m}^{2}$. The thermal capacity of the building varied as a parameter.

Table 1. Default values for dynamic parameters

\begin{tabular}{lcc}
\hline Class & $\begin{array}{c}\text { Simple hourly method, } \\
C_{m},[\mathrm{~J} / \mathrm{K}]\end{array}$ & $\begin{array}{c}\text { Parameter value in } \\
\text { simulation } C_{m},[\mathrm{~J} / \mathrm{K}]\end{array}$ \\
\hline Very light & $80,000 \cdot A_{f}$ & $1,600,000$ \\
\hline Light & $110,000 \cdot A_{f}$ & $2,200,000$ \\
\hline Medium & $165,000 \cdot A_{f}$ & $3,300,000$ \\
\hline Heavy & $260,000 \cdot A_{f}$ & $5,200,000$ \\
\hline Very heavy & $370,000 \cdot A_{f}$ & $7,400,000$ \\
\hline
\end{tabular}

The range of values used was in accordance with the international EN ISO 52016-1 [36] standard, as presented in Table 1.

\subsection{Design Chart Creation}

In order to identify the parameters that ensured the required thermal comfort level, the results of the parametric analysis were used to create design charts. To increase the reusability of the charts, design parameters were normalised or aggregated to the derived parameters.

The main comfort-influencing indicators, such as the building thermal constant, specific area of solar collectors, and heat source capacity, were selected as the main optimisation parameters. The values of these parameters were expressed using the following equations:

- Building thermal constant (in accordance with the EN ISO 52016-1 standard) [36]:

$$
\tau=\frac{C_{m}}{H} .
$$

- Specific area of solar collectors:

$$
A_{S P-S C}=\frac{A_{S C}}{A_{f}} .
$$


The results of the parametric analysis were expressed as three-dimensional surface functions that defined the relationship between system parameters. These were used to describe system efficiency and functionality dependence on primary building and mechanical system properties. The methodology behind the chart structure is shown in Fig. 3.

If these charts are viewed from the perspective of the $\mathrm{Z}$-axis and altitude differences are expressed in isolines the results can be combined in monograms. These monograms can be used to predict a more efficient selection of parameters when designing a building and energy systems that utilise solar energy.

Results of the parametric study were postprocessed using the MATLAB software. The outcome of the study predicted the main dependencies in relation to the comfort level. Figures show the average percentage of people dissatisfied (PPD) values during the heating season. This parameter predicts the functional performance of the heating system from a comfort perspective, considering that the target average PPD value should not exceed $10 \%$.
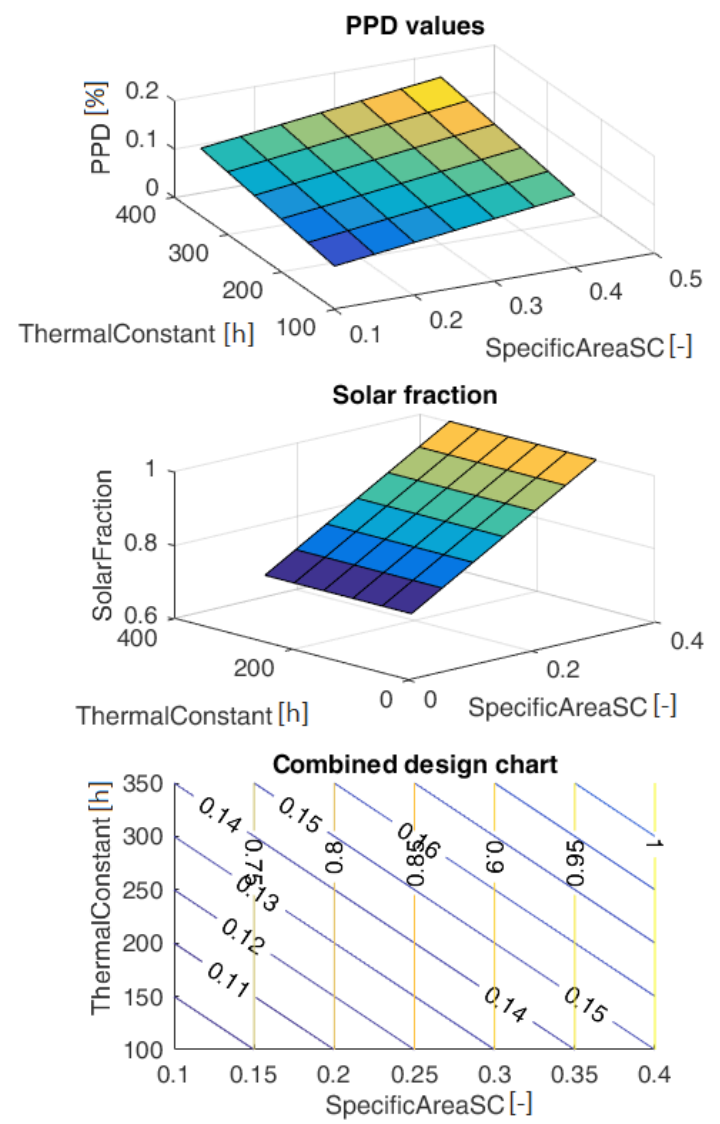

Fig. 3. Workflow of design chart creation on the basis of the proposed method

\section{DESCRIPTION OF THE BUILDING MODEL USED FOR PARAMETRIC ANALYSIS}

The consistency of thermal comfort should be ensured during the entire heating season. The conditions under which the thermal comfort parameter exceeds $10 \%$ indicate that the function of the microclimate system is not satisfied [8]. To maintain comfort for occupants, certain actions are required. The activities that are involved in creating thermal comfort (the main function) typically consume energy or other resources in order to run or create the system.

The simulation model was created in the TRNSYS simulation environment and comfort level calculations were performed using a MATLAB script included in the main simulation tool. TRNSYS is a dynamic simulation tool that was developed over the course of 30 years, with flexibility in modelling systems and buildings. In TRNSYS, a model is developed within the Simulation Studio environment, which is a graphical user modelling interface. This software has a modular structure that was designed to solve complex problems in energy systems by breaking scenarios down into a series of smaller components. These components are known as "types", predefined components and algorithms that model the behaviour of common systems.

The model was saved in the ASCII text format as a "deck" file (*.dck), which stores the "types" and connections between each type. The model was executed using TRNEXE, an algebraic and differential equation solver, which iteratively computes the state of the system at each time step. In this case, it was seven minutes, as it was necessary to reflect the control time constant. Because the model was stored in a text format, it could be parameterised using scripting languages, such as MATLAB. Mathematical models used to perform the simulation in TRNSYS are described in the following subsections of the paper. The macrostructure of the model can be divided into four main hydronic loops (Fig. 4):

1. Solar collector to heat storage;

2. Auxiliary heater to heat storage;

3. Heat distribution network from heat storage to heat emitting devices;

4. Heat emission system in building space.

The main parameter used to measure the efficiency of the design combination was seasonal comfort, as described in the following paragraph. 


\subsection{Comfort}

Measuring how the system functions can best be described as one's sense of comfort while being in the room. Indoor comfort indicators are defined in ISO 7730 [8]. This standard describes the predicted mean vote (PMV) and PPD indices and specifies the acceptable conditions for thermal comfort. The PMV predicts the mean value of the votes from a large group of people on the ISO thermal sensation scale $(+3=$ hot, $0=$ neutral, $-3=$ cold $)$. The PPD predicts the percentage of a large group of people likely to feel "too warm" or "too cool" [37]. PMV is a function that encompasses four environmental variables: air temperature $\left(t_{a}\left[{ }^{\circ} \mathrm{C}\right]\right)$, mean radiant temperature $\left(t_{m r t}\left[{ }^{\circ} \mathrm{C}\right]\right)$, relative air velocity $(v[\mathrm{~m} / \mathrm{s}])$, and air humidity (i.e. vapour pressure, $p_{a}[\mathrm{kPa}]$ ). Activity level (i.e. metabolic rate, $M\left[\mathrm{~W} / \mathrm{m}^{2}\right]$ ) and clothing insulation $\left(I_{c l}\right.$ [clo]) are also considered [38]. Thus:

$$
P M V=f\left(t_{a}, t_{m r t}, p_{a}, M, I_{c l}, v\right) .
$$

It is important to know the percentage of people who are dissatisfied with the environment, as it represents the most likely source of complaints. Based on experimental studies in which participants voted on thermal sensations, an empirical relationship between PMV and the predicted percentage of dissatisfied occupants (PPD) was developed as follows [38]:

$$
P P D=100-95 \cdot \exp \left(-0.3353 P M V^{4}-0.219 P M V^{2}\right)
$$

Eq. (4) indicates that even at thermal neutrality (i.e. $P M V=0), 5 \%$ of occupants may still be dissatisfied.

Comfort conditions are often tested over longer periods of time, for different types of buildings, and/ or heating, ventilation, and air conditioning (HVAC) design with the assistance of computer simulation. It is necessary to quantify the long-term comfort conditions based on an index, such that alternative designs can be compared. For these purposes, the following method is recommended in future revisions of the standards [37].

The time during which the actual PMV exceeds the comfort boundaries was considered by using a factor that is a function of the PPD. Starting with the PMV distribution on an annual basis and the relation between PMV and PPD, the following was calculated:

$$
w f=\frac{P P D_{\text {actual } P M V}}{P P D_{P M V \text { limit }}},
$$

where $P P D_{\text {actual } P M V}$ is the PPD corresponding to the actual PMV and $P P D_{P M V \text { limit }}$ is the PPD corresponding to the PMV limit.

For a characteristic period during a year, the product of the weighting factor, $w f$, and the time, $\mathrm{t}$, were added and the result was expressed in hours:

- $\quad$ warm period: $\Sigma w f \cdot \cdot$ time, where $P M V>P M V_{\text {limit }}$,

- cold period: $\Sigma w f \cdot t$ time, where $P M V<P M V_{\text {limit }}$.

The summation of the product of "weighing factor $\times$ time" was termed "weighted time" [h]. These values were used to evaluate long term comfort conditions and acceptable weighting times of, for example, $100 \mathrm{~h}$ to $150 \mathrm{~h} \mathrm{[37].} \mathrm{Comfort} \mathrm{level}$ calculations were performed using a script run in the MATLAB environment. This process was integrated into TRNSYS parametric simulations via Type 155 . Thermal environmental assessment was conducted in the B category, with PMV $= \pm 0.5$ and $\mathrm{PPD}<10 \%$, where $T_{a}=22 \pm 0.5^{\circ} \mathrm{C}$. The calculation adopted the following assumptions [8]:

- $M=58.15 \mathrm{~W} / \mathrm{m}^{2}$ or 1 met

- $W=0 \mathrm{~W} / \mathrm{m}^{2}$

- $I_{c l}=0.155 \mathrm{~m}^{2} \cdot \mathrm{K} / \mathrm{W}$ or 1 clo

- $v=0.116 \mathrm{~m} / \mathrm{s}$

$M, W, I_{c l}$, and $\mathrm{v}$ remained constant during the heating season, due to low variability and limited possibilities of predicting the variations. This was due to the uncertainty related to occupant behaviour (for $M, W, I$ ) and the complexity of air movement in the room. Other parameters, such as air temperature, radiant temperature, and relative humidity, were considered to be variables and were simulated in the model as an outcome of building and ventilation unit subsystems.

The air and radiant temperatures were highly influenced by the passive and active systems. Solar radiation through glazed surfaces increased the mean radiant temperature and was accumulated in the thermal mass. Active systems influenced the air and radiant temperature through the underfloor heating and the impact on air temperature. Relative humidity varied during the heating season, due to different water vapour content in the external environment.

In order to generate the variables required to assess thermal comfort, a simulation model using multiple TRNSYS components was created (see Fig. 4). The mathematical models used in these components are described in the following sections. The TESS libraries were used for model creation [39]. 


\subsection{Building Space Model}

A lumped capacitance building of Type 88 represented a single-space thermal zone with internal gains. It was selected for the study, due to the possibility of including humidity exchange as well as its computational speed, due to relatively simple heat and humidity balances. This component modelled a simple lumped capacitance single-zone structure that was subject to internal gains. It differed from other simple building models since it made no assumption about the control scheme. Furthermore, it assumed an overall $U$ value for the entire structure. Its usefulness originates from the speed with which a building heating and/or cooling load can be added to a system simulation. While this type itself did not include solar gains, this heat balance component was added as a heat source from Type 687 [39]. This calculated the amount of solar energy and illumination transmitted through a window given only the basic information - the overall $U$ value and solar heat gain coefficient (SHGC), as well as visual transmittance.

Components of air exchange heating balance were separated into two parts: air exchange caused by infiltration and mechanical ventilation with heat recovery. Infiltration air exchange was modelled as a variable velocity when the difference in air tightness of the building at $50 \mathrm{~Pa}$ was equal to $0.6 \mathrm{~h}^{-1}$. This effect was included via Type 932, which used the Sherman Grimsrud Infiltration Model described in the ASHRAE Handbook of Fundamentals [40]. The model based the effects of infiltration on an effective leakage area, indoor/outdoor temperature difference, and wind speed.

Type 1231 modelled low-temperature hydronic heat-distributing units, such as radiators, convectors, baseboards, and finned-tube units. These types of units supply heat through a combination of radiation and convection without fans. The mathematical model implemented in this type was based on the method presented in the ASHRAE Handbook - HVAC Systems and Equipment.[41]

The combination of Type 112 and Type 667 represented fans with absolute humidity input and a sensible air-to-air heat exchanger [41]. Type 6 was an auxiliary heater that elevates the temperature of the flow stream when the temperature decreased below the set point. It operated similar to an externally controlled ON/OFF heating device. Energy is delivered to the hot storage tank via an immersed heat exchanger. The heating capacity of the auxiliary (electrical) heater varied from $15 \mathrm{~W} / \mathrm{m}^{2}$ to $30 \mathrm{~W} / \mathrm{m}^{2}$ and the set point temperature was set at $35^{\circ} \mathrm{C}$.

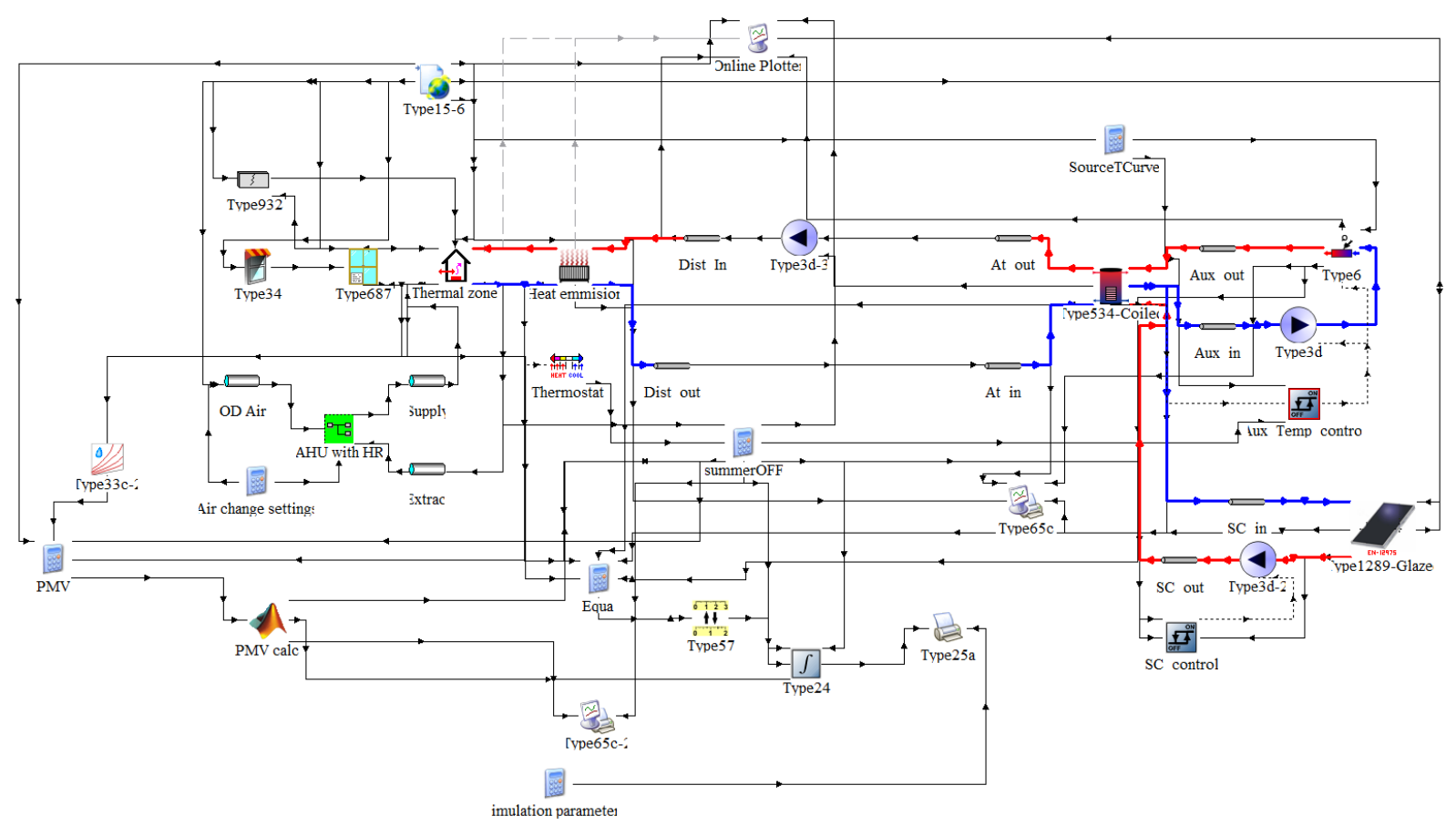

Fig. 4. Simulation model in TRNSYS environment 


\subsection{Solar Collectors}

Flat plate solar collectors were modelled on the basis of Type 1289 , which calculated dynamic efficiency as a function of inlet temperature that could be obtained using the Hottel-Whillier equation:

$$
\eta=\eta_{0}-a_{1} \frac{\left(T_{i n}-T_{a m b}\right)}{I_{T}}-a_{2} \frac{\left(T_{i n}-T_{a m b}\right)^{2}}{I_{T}} .
$$

The main properties defining solar collector specifications used for the simulation are listed below:

- type, flat plate solar collectors,

- $\quad$ optical efficiency, $80.4 \%$,

- heat loss coefficient $a_{1}, 3.235 \mathrm{~W} /\left(\mathrm{m}^{2} \mathrm{~K}\right)$,

- heat loss coefficient $a_{2}, 0.0117 \mathrm{~W} /\left(\mathrm{m}^{2} \mathrm{~K}^{2}\right)$,

- thermal capacity $\mathrm{C}, 5.85 \mathrm{~kJ} /\left(\mathrm{m}^{2} \mathrm{~K}\right)$,

- $\quad$ azimuth, $0^{\circ}$ (south),

- inclination, $65^{\circ}$.

\subsection{Heat Storage}

Heat storage was modelled as a stratified storage tank with 10 nodes (Type 534). The overall tank loss coefficient was assumed to be $0.4 \mathrm{~W} /\left(\mathrm{m}^{2} \cdot \mathrm{K}\right)$. The fluid in the storage tank interacted with the fluid in the heat exchangers (through heat transfer with the immersed heat exchangers), with the environment (through thermal losses from the top, bottom, and edges), and with the flow stream that enters and exits the storage tank. The storage tank was divided into isothermal temperature nodes. Each constant-volume node was assumed to be isothermal and to interact thermally with the nodes above and below through several mechanisms: fluid conduction between nodes and fluid movement due to destratification effects.

The volume of the accumulation tank was assumed to depend on the solar collector area $\left(A_{S C}\right)$ and can be expressed as shown in Eq. (4).

$$
V_{\text {accumulation }}=0.07 \cdot A_{S C} \text {, }
$$

where 0.07 is the specific accumulation tank volume per $1 \mathrm{~m}^{2}$ of the solar collector area.

\section{MODEL VERIFICATION PROCEDURES}

For engineered systems, terminology such as "virtual prototyping" and "virtual testing" is now used in development to describe numerical simulation for the design, evaluation, and "testing" of new hardware and systems. Virtual testing is a more reasonable way to ensure proper operation and performance than building and testing a physical system. The potential legal and liability costs of failures can be staggering to a company, the environment, or the public, when building inappropriate systems without virtual testing [42].

The limitation of the proposed method is the uncertainty of predicted results. In order to control this aspect, the following validation procedures should be performed:

1. Build parametric models from verified simulation models/components.

2. Numerical errors occurring due to precision and simulation parameters should not exceed $5 \%$ of the final result value.

3. Ensure that mass flow and energy balances are satisfied in system simulations.

4. Verify that thermal comfort parameters are in accordance with EN ISO 7730 acceptable ranges.

As there was no available analytical solution or experimental data for the given system configuration, only separate component verifications could be performed. The evidence of how accurately the computational model simulates reality could thus be based on separate element verification procedures previously performed for the components used in the case studies building space [43], solar thermal collectors [44] and accumulation tank [45].

The given aspects showed that the results were sufficiently accurate for initial predictions. The next stage of the design process was to perform a more detailed simulation to measure the building performance for load sizing, energy consumption predictions, and other activities typically performed in the design process.

\section{RESULTS AND DISCUSSION}

As an example, Fig. 4 shows the dependence of $P P D_{\text {avg }}$ on a specific area of solar collectors and the building thermal constant. The specific area of solar collector was the ratio between the solar collector area and the floor area. The dependence of solar fraction on the same parameters is depicted in Fig. 5.

In Fig. 6, the fifth (5) surface represents the $P P D_{\text {avg }}$ values at full heat source capacity $\left(30 \mathrm{~W} / \mathrm{m}^{2}\right)$. The fourth (4) surface represents the same result, but using $7 / 8$ of the required heat source capacity $(26.25$ $\left.\mathrm{W} / \mathrm{m}^{2}\right)$. The third (3) used $3 / 4\left(22.5 \mathrm{~W} / \mathrm{m}^{2}\right)$, the second (2) used $5 / 8\left(18.75 \mathrm{~W} / \mathrm{m}^{2}\right)$, and the first (1) used $1 / 2$ $\left(15 \mathrm{~W} / \mathrm{m}^{2}\right)$ of the required capacity. 


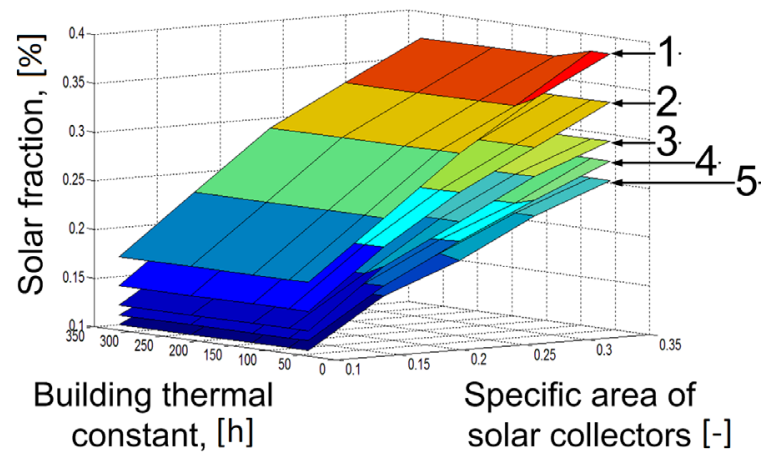

Fig. 5. Change of PPD with varying heat source power

The red plane represents the boundary where $P P D_{\text {avg }}$ has a constant $10 \%$ value. Results above this boundary were considered unsatisfactory in terms of thermal comfort in the room $\left(P P D_{\text {avg }}>10 \%\right)$.

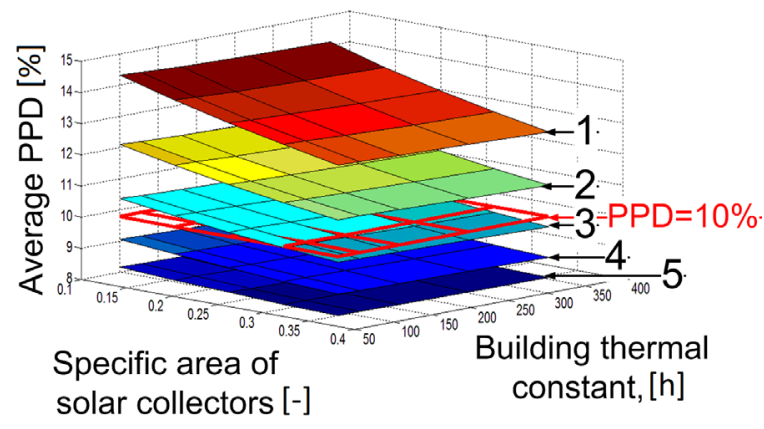

Fig. 6. Change of $f_{\text {sol }}$ with varying source power

In Fig. 6, the fifth surface (5) represents the solar fraction values when $1 / 2$ of the required heat source capacity $\left(15 \mathrm{~W} / \mathrm{m}^{2}\right)$ was used. The fourth surface (4) represents the same quantity at $5 / 8$ of the required capacity $\left(18.75 \mathrm{~W} / \mathrm{m}^{2}\right)$, the third (3) represents $3 / 4$ of the required capacity $\left(22.5 \mathrm{~W} / \mathrm{m}^{2}\right)$, the second (2) was $7 / 8\left(26.25 \mathrm{~W} / \mathrm{m}^{2}\right)$, and the first (1) represents the full heat source capacity $\left(30 \mathrm{~W} / \mathrm{m}^{2}\right)$.

Fig. 7 represents the $P P D_{\text {avg }}$ and solar fraction when the capacity was $1 / 2\left(15 \mathrm{~W} / \mathrm{m}^{2}\right)$ of the heat source required $\left(30 \mathrm{~W} / \mathrm{m}^{2}\right)$ in accordance with regular sizing methods. Figs. 6 and 7 represent the same quantities as depicted in Fig. 5. The heat source capacities of $3 / 4\left(22.5 \mathrm{~W} / \mathrm{m}^{2}\right)$ and $7 / 8\left(26.25 \mathrm{~W} / \mathrm{m}^{2}\right)$ were used for the room space heating load.

The $P P D_{\text {avg }}$ reached an acceptable level when the heat source capacity values were $5 / 8(18.75$ $\left.\mathrm{W} / \mathrm{m}^{2}\right)$ and $1.0\left(30 \mathrm{~W} / \mathrm{m}^{2}\right)$ of the required heat source capacity. These relations are shown as dashed isolines. Continuous isolines represent the solar fraction under given conditions.
Fig. 7 shows that increasing the thermal constant and the specific area of solar collectors contributed to the improvement of the average PPD value for the heating season (from $14.4 \%$ to $12.8 \%$ ). Thus, the number of unsatisfied people decreased. The PPD value varied from $12.2 \%$ to $11.2 \%$ when the heat source was at $5 / 8$ of the required capacity (18.75 $\mathrm{W} / \mathrm{m}^{2}$ ). The increase of specific area of solar collectors influenced the comfort level and solar fraction.

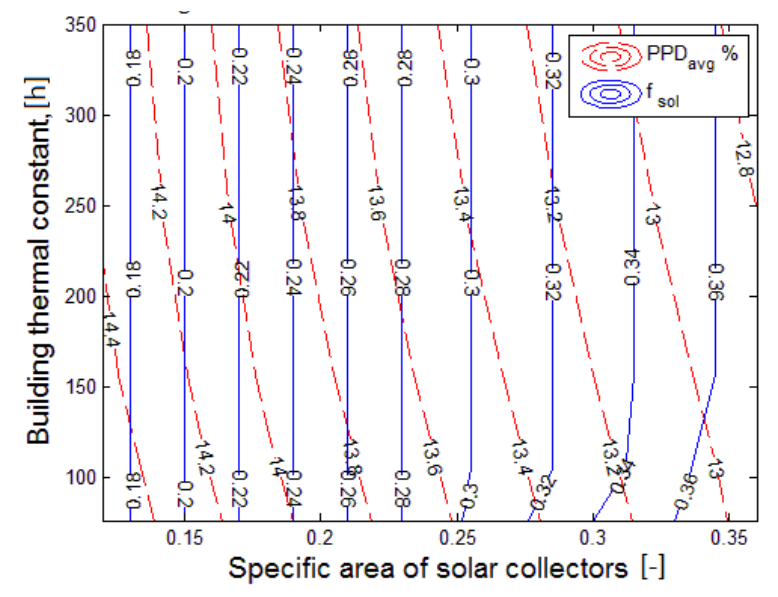

Fig. 7. Change of $P P D$ and solar fraction $\left(f_{\text {sol }}\right)$ when heat source power is $15 \mathrm{~W} / \mathrm{m}^{2}$

This behaviour was quite predictable, due to the increased possibilities of solar utilisation that involve a greater solar collector area. It is important to emphasise that this combination of thermal constant and the specific area of solar collectors ensures the highest comfort level, while using the lowest amount of energy. A heat source that covered only a half of the required heating capacity (Fig. 7) could help to achieve a much higher solar fraction (0.36). 5/8 of the required capacity achieved a solar fraction equal to 0.32 , but had a greater comfort level in comparison to $1 / 2$ of the required capacity, even though the average heating season temperature was above $20^{\circ} \mathrm{C}$. In this case, the duration of discomfort (PPD $>10 \%$ ) lasted for $17 \%$ of the heating season and, depending on design parameters, varied from $16 \%$ to $18 \%$. In the second case $\left(18.75 \mathrm{~W} / \mathrm{m}^{2}\right)$, the discomfort varied from $14 \%$ to $15 \%$ for the assessment period.

Fig. 8 shows how $P P D_{\text {avg }}$ and $f_{\text {sol }}$ depend on the same parameters when the heat source is designed to meet 3/4 of capacity. In this graph the breaking point was identified by increasing the thermal constant and the specific area of solar collectors if $P P D_{\text {avg }}$ was acceptable and the number of dissatisfied people dropped below $10^{\circ} \%$ (see the shaded area in Fig. 8). The highest achievable solar fraction was equal to 
0.26 . Under these conditions, comfort conditions were not maintained for $14 \%$ to $15 \%$ of the heating season.

In cases when $7 / 8$ and full required capacity were used $\left(30 \mathrm{~W} / \mathrm{m}^{2}\right), P P D_{\text {avg }}$ reached acceptable levels under all design parameter combinations (see Fig. 9). Solar fractions of 0.26 and 0.24 were achieved, respectively. Comfort requirements were not met for $10 \%$ to $12 \%$ of the heating season.

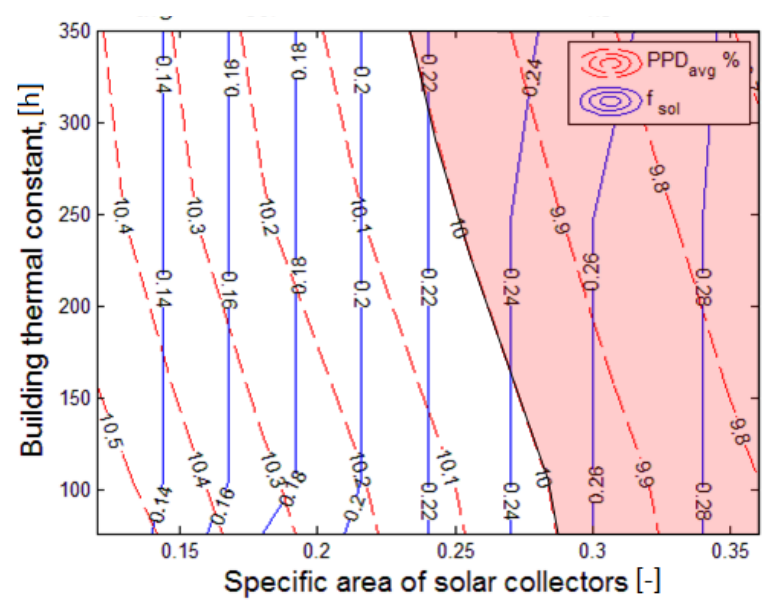

Fig. 8. Change of $P P D$ and solar fraction $\left(f_{\text {sol }}\right)$ when heat source power is $22.5 \mathrm{~W} / \mathrm{m}^{2}$

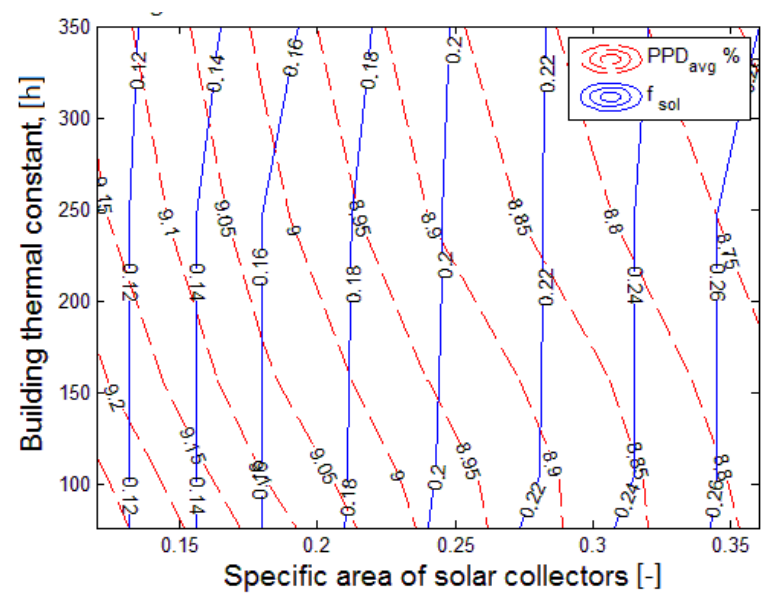

Fig. 9. Change of $P P D$ and solar fraction $\left(f_{\text {sol }}\right)$ when heat source power is $26.25 \mathrm{~W} / \mathrm{m}^{2}$

Having expressed the PPD and solar fraction values as functions of space heating capacity and the specific area of solar collectors, a chart depicting relevant relations was produced (Fig. 10). Due to the low impact of the thermal constant, the value of PPD, restricted under given conditions $(10 \%)$, varied slightly (see the shaded area in Fig. 10). For the purposes of simplification, the dependency is shown at the thermal constant of 156 hours, which is the median value of the range examined.

The isoline showing $10 \%$ of dissatisfied people decreased in relation to the solar collector area. Thus, the lack of space heating capacity could be compensated for by an energy-efficient building that satisfies the requirements stated in the assumptions of this study. In this case, solar collectors could supply 0.14 to 0.29 of the required heat demand during the heating season.

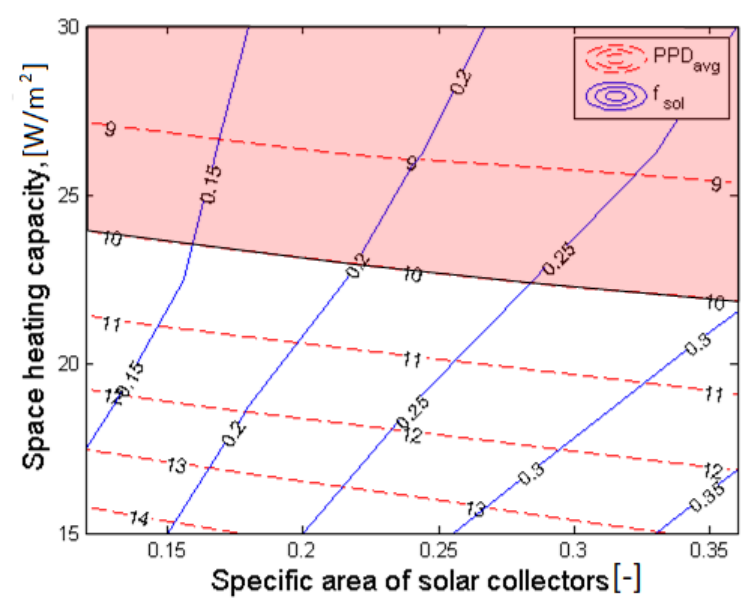

Fig. 10. $P P D$ and solar fraction $\left(f_{\text {sol }}\right)$ dependence on heating capacity and specific solar collector area

The combination of higher thermal mass and specific area of solar collectors helped to decrease the installed heating source capacity without having a detrimental effect on thermal comfort. This study showed that the highest solar fraction was ensured when the space heating source capacity was at its lowest. Under these conditions, the thermal comfort level was not ensured (the PPD was $17 \%$ ). This combination of design parameters cannot be used, since it is not acceptable from the perspective of comfort level.

In the best case presented in this paper, the comfort level was not ensured for $10 \%$ of the heating season, while space temperature was at $22 \pm 2{ }^{\circ} \mathrm{C}$. This shows that temperature was important, but it was not the only parameter since thermal discomfort can be caused by relative humidity and radiant temperature as well. From a global perspective, air velocity significantly influenced comfort level, but in this case it was assumed to be constant. A combination of these parameters led to difficulties in ensuring the comfort level throughout the heating season. 


\section{CONCLUSIONS}

In this paper, functionality was defined by the PPD, which was aggregated to reflect seasonal dissatisfaction related to thermal comfort. This approach allowed for design parameters to be determined that ensured an acceptable degree of functional satisfaction. The main conclusions of this research are as follows:

1. Separate efforts to explore passive and active heat accumulation and solar energy utilisation, as well as thermal comfort were observed in the research. The integrated approach suggested in the paper, however, has not been identified in the conducted literature analysis.

2. By using the proposed method, designers are able to create a complex solution, which takes into account multiple aspects that influence the thermal comfort level. The method establishes a connection between different design parameters (as variables) and enables the identification of synergies between different active and passive strategies in order to satisfy the function of thermal comfort. The method has the following strengths:

- Generation of the design charts requires a onetime effort and the knowledge of interactions can be reused.

- The method replaces intuitive rule-of-thumb methods and increases clarity and transparency in the initial design process.

- The design method allows for the identification of possible trade-offs between different approaches using passive and active solar and heat accumulation utilisation techniques.

- It provides a tool for sustainability-conscious designers to implement a combination of passive and active utilisation of solar energy with heat accumulation.

3. High level certainty is not required, due to the tolerated accuracy margin at the early stages of the design process. The simplifications and assumptions are considered to a certain extent to reflect the trends of systems and coupled interactions. The main sources of uncertainty in the outcome of the design method are the assumptions used to create the simulation model, as well as its validity in comparison to reality.

4. The results of the created case study showed that the estimated optimal heat source capacity was $22.5 \mathrm{~W} / \mathrm{m}^{2}$. In relation to the specific area of solar collectors and the available building thermal constant PPDavg values, this capacity was lower than $10 \%$. The highest solar fraction $(0.36)$ was achieved when the heating source capacity was at its lowest $\left(15 \mathrm{~W} / \mathrm{m}^{2}\right)$, but thermal comfort requirements were not met $\left(P P D_{\text {avg }}\right.$ is higher than $10 \%$ ), thus, this design option should be avoided.

\section{FUTURE WORK}

The strength of the proposed method lies in the fact that it enables quick selection of building and microclimate system characteristics in the early design stages. The limitation of this method is the computational cost required to generate the design charts. The costs may increase if additional variables are included. The normalisation of design variables and the possibility of reusing the design charts creates value for the design process.

Further improvements to the design chart algorithm might be achieved by including additional design variables. In order to decrease the computational cost of generating design charts, the parametric analysis could be upgraded to a combination search based on multi-objective optimisation. As the thermal comfort models evolve to include methods based on the second law of thermodynamics [46] and [47], further work may lead to design charts using exergybased definitions [48].

\section{ACKNOWLEDGEMENTS}

The authors would like to express their appreciation to the Laboratory of Building Energy and Microclimate Systems (Vilnius Gediminas Technical University) for providing the TRNSYS and MATLAB software tools.

\section{NOMENCLATURE}

$C_{m}$ building thermal capacity, $[\mathrm{J} / \mathrm{K}]$

$H$ building specific heat loss, $[\mathrm{W} / \mathrm{K}]$

$\tau$ thermal constant of the building, [h]

$A_{f}$ heated floor area, $\left[\mathrm{m}^{2}\right]$

$A_{S C}$ area of solar collectors, [ $\left.\mathrm{m}^{2}\right]$

$\eta \quad$ thermal efficiency of solar thermal collectors, [-]

$\eta_{0}$ optical efficiency of solar thermal collectors, [-]

$a_{1}$ loss coefficient of solar thermal collectors, $\left[\mathrm{W} /\left(\mathrm{m}^{2} \cdot \mathrm{K}\right)\right]$

$a_{2}$ loss coefficient of solar thermal collectors, $\left[\mathrm{W} /\left(\mathrm{m}^{2} \cdot \mathrm{K}^{2}\right)\right]$

$T_{\text {in }}$ inlet temperature of solar collectors, $\left[{ }^{\circ} \mathrm{C}\right]$

$T_{a m b}$ ambient temperature, $\left[{ }^{\circ} \mathrm{C}\right]$

$I_{T}$ incident solar radiation, $\left[\mathrm{W} / \mathrm{m}^{2}\right]$

$\Delta T$ temperature, $[\mathrm{K}]$

$t_{a}$ temperature of the thermal zone, $\left[{ }^{\circ} \mathrm{C}\right]$ 
$t_{m r t}$ mean radiant temperature of thermal zone, $\left[{ }^{\circ} \mathrm{C}\right]$

$p_{a}$ vapour pressure, $[\mathrm{Pa}]$

$M$ metabolic rate, $\left[\mathrm{W} / \mathrm{m}^{2}\right]$

$I_{c l} \quad$ clothing level of occupants, [clo]

$V_{a c}$ volume of active accumulation tank, $\left[\mathrm{m}^{3}\right]$

$P P D$ percentage of people dissatisfied at specific time step, [\%]

$P P D_{\text {avg }}$ average seasonal percentage of people dissatisfied, [\%]

$P M V$ predicted mean vote, [-]

$w_{f}$ weight factor for seasonal thermal comfort calculation, [-]

\section{REFERENCES}

[1] United Nations (2015). Transforming our world: the 2030 Agenda for Sustainable Development, from https://sustainabledevelopment.un.org/post2015/ transformingourworld, accessed on 2018-10-08.

[2] United Nations (2015). About the Sustainable Development Goals, from https://www.un.org/sustainabledevelopment/ sustainable-development-goals/, accessed on 2018-10-08.

[3] European Commission (2018). The energy performance of buildings directive, from https://ec.europa.eu/info/sites/ info/files/epbd_factsheet_20180503_dc_v03e_final.pdf, accessed on 2018-10-08.

[4] European Commission (2018). Heating and cooling, from https://ec.europa.eu/energy/en/topics/energy-efficiency/ heating-and-cooling, accessed on 2018-10-08.

[5] 2010/31/EU (2016). Proposal for a Directive of the European Parliament and of the Council amending Directive 2010/31/ $E U$ on the energy performance of buildings. European commission, Brussels, D0I:10.1007/978-1-137-54482-7_33.

[6] EN 12973:2000 Value management. International Organization for standardization. Brussels.

[7] Cook, R. (2007). Integrated Project Delivery a Guide. The American Institute of Architects, Chicago.

[8] EN ISO 7730:2005. Ergonomics of the thermal environment - Analytical determination and interpretation of thermal comfort using calculation of the PVM and PPD indices and local thermal comfort criteria. International Organization for standardization. Geneva, D0l:10.3403/30046382.

[9] Megri, A.C., El Naqa, I. (2016). Prediction of the thermal comfort indices using improved support vector machine classifiers and nonlinear kernel functions. Indoor and Built Environment, vol. 25, no. 1, p. 6-16, D0l:10.1177/1420326X14539693.

[10] Pathak, P.M., Dongre, A.R., Shiwalkar, J.P. (2014). Impact of spatial, thermal and lighting parameters on the efficiency and comfort of users in Indian workspaces. Journal of Sustainable Development, vol. 7, no. 4, p. 111-123, D0l:10.5539/jsd. v7n4p111.

[11] Dovjak, M., Slobonik, J., Krainer, A. (2019). Deteriorated indoor environmental quality as a collateral damage of present day extensive renovations. Strojniški vestnik Jurnal of Mechanical Engineering, vol. 65, no. 1, p. 31-40. DOI:10.5545/sv-jime2018.5384.
[12] Al horr, Y., Arif, M., Katafygiotou, M., Mazroei, A., Kaushik, A., Elsarrag, E. (2016). Impact of indoor environmental quality on occupant well-being and comfort: A review of the literature. International Journal of Sustainable Built Environment, vol. 5, no. 1, p. 1-11, D0I:10.1016/j.ijsbe.2016.03.006.

[13] Leccese, F., Salvadori, G., Asdrubali, F., Gori, P. (2018). Passive thermal behaviuor of buildings: Performance of external multilayered walls and influence of internal walls. Applied Energy, vol. 225, p. 1078-1089, D0l:10.1016/j.apenergy.2018.05.090.

[14] Borel, L., Favrat, D. (2010). Thermodynamics and Energy Systems Analysis: From Energy to Exergy. Taylor and Francis Group, Boca Raton.

[15] Orosa, J.A., Oliveira, A.C. (2012). A field study on building inertia and its effects on indoor thermal environment. Renewable Energy, vol. 37, no. 1, p. 89-96, Dol:10.1016/j. renene.2011.06.009.

[16] Passipedia (2016). The Passive House - definition, from https://passipedia.org/basics/the_passive_house_-definition, accessed on 2016-06-02.

[17] Stazi, F., Bonfigli, C., Tomassoni, E., Di Perna, C., Munafò, P. (2015). The effect of high thermal insulation on high thermal mass: Is the dynamic behaviour of traditional envelopes in Mediterranean climates still possible? Energy and Buildings, vol. 88, p. 367-383, D0l:10.1016/j.enbuild.2014.11.056.

[18] Buker, M.S., Riffat, S.B. (2015). Building integrated solar thermal collectors - A review. Renewable and Sustainable Energy Reviews, vol. 51, p. 327-346, D0l:10.1016/j. rser.2015.06.009.

[19] Aste, N., Angelotti, A., Buzzetti, M. (2009). The influence of the external walls thermal inertia on the energy performance of well insulated buildings. Energy and Buildings, vol. 41, no. 11, p. 1181-1187, D0I:10.1016/J.enbuild.2009.06.005.

[20] Albayyaa, H., Hagare, D., Saha, S. (2019). Energy conservation in residential buildings by incorporating passive solar and energy efficiency design strategies and higher thermal mass. Energy and Buildings, vol. 182, p. 205-213, D0l:10.1016/j. enbuild.2018.09.036.

[21] Bajc, T., Todorović, M.N., Svorcan, J. (2014). CFD analyses for passive house with Trombe wall and impact to energy demand. Energy and Buildings, vol. 98, p. 39-44, Dol:10.1016/j. enbuild.2014.11.018.

[22] Dong, J., Chen, Z., Zhang, L., Cheng, Y., Sun, S., Jie, J. (2019). Experimental investigation on the heating performance of a novel designed trombe wall. Energy, vol. 168, p. 728-736, Dol:10.1016/j.energy.2018.11.125.

[23] Kontoleon, K.J., Theodosiou, Th.G. Tsikaloudaki, K.G. (2013). The influence of concrete density and conductivity on walls' thermal inertia parameters under a variety of masonry and insulation placements. Applied Energy, vol. 112, p. 325-337, DOI:10.1016/J.apenergy.2013.06.029.

[24] Asan, H., Sancaktar, Y.S. (1998). Effects of Wall's thermophysical properties on time lag and decrement factor. Energy and Buildings, vol. 28, no. 2, p. 159-166, Dol:10.1016/ S0378-7788(98)00007-3.

[25] Al-Sanea, S.A., Zedan, M.F. (2011). Improving thermal performance of building walls by optimizing insulation layer distribution and thickness for same thermal mass. 
Applied Energy, vol. 88, no. 9, p. 3113-3124, D0l:10.1016/j. apenergy.2011.02.036.

[26] Ling, H., Chen, C., Guan, Y., Wei, S., Chen, Z., Li, N. (2014). Active heat storage characteristics of active-passive triple wall with phase change material. Solar Energy, vol. 110, p. 276-285, D0I:10.1016/J.solener.2014.09.015.

[27] Guarino, F., Athienitis, A., Cellura, M., Bastien, D. (2017). PCM thermal storage design in buildings: Experimental studies and applications to solaria in cold climates. Applied Energy, vol. 185, p. 95-106, D0l:10.1016/j.apenergy.2016.10.046.

[28] Alghoul, M.A., Sulaiman, M.Y., Sopian, K., Azmi, B.Z. (2009). Performance of a dual-purpose solar continuous adsorption system. Renewable Energy, vol. 34, no. 3, p. 920-927, DOI:10.1016/j.renene.2008.05.037.

[29] Ampatzi, E., Knight, I., Wiltshire, R. (2013). The potential contribution of solar thermal collection and storage systems to meeting the energy requirements of North European Housing. Solar Energy, vol. 91, p. 402-421, D0l:10.1016/j. solener.2012.09.008.

[30] Andersen, E., Chen, Z., Fan, J., Furbo, S., Perers, B. (2014). Investigations of intelligent solar heating systems for single family house. Energy Procedia, vol. 48, p. 1-8, D0l:10.1016/j. egypro.2014.02.002.

[31] Artur, C., Neves, D., Cuamba, C.B., Leao, J.A. (2018). Comparison of two dynamic approaches to modelling solar thermal systems for domestic hot water. Sustainable Energy Technologies and Assessments, vol. 30, p. 292-303, D0I:10.1016/j.seta.2018.10.012.

[32] Garnier, C., Muneer, T., Currie, J. (2018). Numerical and empirical evaluation of a novel collector storage solar water heater. Renewable Energy, vol. 126, p. 281-295, DOl:10.10.16/j.renene.2018.03.041.

[33] Lugaric, L., Majdandžic, L., Škrlec, D. (2010). Countrywide positioning of domestic solar water heating systems using risk analysis and geographical information system. Strojniški vestnik - Journal of Mechanical Engineering, vol. 53, no. 1, p. 3-17.

[34] Yan, C., Wang, S., Ma, Z., Shi, W. (2015). A simplified method for optimal design of solar water heating systems based on life-cycle energy analysis. Renewable Energy, vol. 74, p. 271278, D0I:10.1016/j.renene.2014.08.021.

[35] Fanger, P.O. (1970) Thermal Comfort. Danish Technical Press. Copenhagen.

[36] ISO 52016-1:2017. Energy needs for heating cooling, internal temperatures and sensible and latent heat loads - Part 1: Calculation procedures. International Organization for Standardization. Geneva, DOI:10.3403/30303578u.
[37] Olesen, B.W., Parsons, K.C. (2002). Introduction to thermal comfort standards and to the proposed new version of EN ISO 7730. Energy and Buildings, vol. 34, no. 6, p. 537-548, DOI:10.1016/S0378-7788(02)00004-X.

[38] Yang, L., Yan, H., Lam, J.C. (2014). Thermal comfort and building energy consumption implications - A review. Applied Energy, vol. 115, p. 164-173, D0l:10.1016/j. apenergy.2013.10.062.

[39] Thomton, J.W., Bradley, D.E., McDowell, T.P., Blair, N.J., Duffy, M.J., LaHam, N., Naik, A.V. (2012). TESSLibs 17, vol. 6, p. 1-262.

[40] ASHRAE Handbook (2001). Fundamentals. American Society of Heating, Refrigerating and Air-Conditioning Engineers (ASHRAE), Atlanta.

[41] ASHRAE Handbook (2016). HVAC Systems and Equipment. American Society of Heating Refrigeration and Air Conditioning Engineers (ASHRAE), Atlanta.

[42] Oberkampf, W.L, Trucano, T.G. (2002). Verification and validation in computational fluid dynamics. Progress in Aerospace Sciences, vol. 38, no. 3, p. 209-272, Dol:10.1016/ S0376-0421(02)00005-2.

[43] Neymark, J., Judkoff, R., Knabe, G., Le, H.T., Dürig, M., Glass, A., Zweifel, G. (2002). Applying the building energy simulation test (BESTEST) diagnostic method to verification of space conditioning equipment models used in whole-building energy simulation programs. Energy and Buildings, vol. 34, no. 9, p. 917-931, D0I:10.1016/S0378-7788(02)00072-5.

[44] Plantier, C., Fraisse, G, Achard, A. (2007). Development and experimental validation of a detailed flat-plate solar collector model. Researchgate.

[45] Cruickshank, C.A. (2009). Evaluation of a stratified multi-tank thermal storage for solar heating applications. PhD thesis. Queen's University. Kingston.

[46] Schweiker, M., Kolarik, J., Dovjak, M., Shukuya, M. (2016). Unsteady-state human-body exergy consumption rate and its relation to subjective assessment of dynamic thermal environments. Energy and Buildings, vol. 116, p. 164-180, D0l:10.1016/j.enbuild.201.01.002.

[47] Prek, M., Butala, V. (2010). Principles of exergy analysis of human heat and mass exchange with the indoor environment. International Journal of Heat and Mass Transfer, vol. 53, no. 25-26, p. 5806-5814, D0l:10.1016/J.ijheatmasstrabsfer. 2010.08.003.

[48] Dovjak, M., Shukuya, M., Krainer, A. (2015). Connective thinking on building envelope - Human body exergy analysis. International Journal of Heat and Mass Transfer, vol. 90, p. 1015-1025, D0I:10.1016/J.jigheatmasstransfer.2015.07.021. 